\title{
Use of Accumulated Entropies for Automated Detection of Congestive Heart Failure in Flexible Analytic Wavelet Transform Framework Based on Short-Term HRV Signals
}

\author{
Mohit Kumar ${ }^{1}$, Ram Bilas Pachori ${ }^{1, *}$ and U. Rajendra Acharya ${ }^{2,3,4}$ \\ 1 Discipline of Electrical Engineering, Indian Institute of Technology Indore, Indore 453552, India; \\ phd1401202005@iiti.ac.in \\ 2 Department of Electronics and Computer Engineering, Ngee Ann Polytechnic, Singapore 599489, Singapore; \\ aru@np.edu.sg \\ 3 Department of Biomedical Engineering, School of Science and Technology, SIM University, \\ Singapore 599491, Singapore \\ 4 Department of Biomedical Engineering, Faculty of Engineering, University of Malaya, \\ Kuala Lumpur 50603, Malaysia \\ * Correspondence: pachori@iiti.ac.in \\ Academic Editor: Herbert Jelinek \\ Received: 25 January 2017; Accepted: 16 February 2017; Published: 27 February 2017
}

\begin{abstract}
In the present work, an automated method to diagnose Congestive Heart Failure (CHF) using Heart Rate Variability (HRV) signals is proposed. This method is based on Flexible Analytic Wavelet Transform (FAWT), which decomposes the HRV signals into different sub-band signals. Further, Accumulated Fuzzy Entropy (AFEnt) and Accumulated Permutation Entropy (APEnt) are computed over cumulative sums of these sub-band signals. This provides complexity analysis using fuzzy and permutation entropies at different frequency scales. We have extracted 20 features from these signals obtained at different frequency scales of HRV signals. The Bhattacharyya ranking method is used to rank the extracted features from the HRV signals of three different lengths (500, 1000 and 2000 samples). These ranked features are fed to the Least Squares Support Vector Machine (LS-SVM) classifier. Our proposed system has obtained a sensitivity of $98.07 \%$, specificity of $98.33 \%$ and accuracy of $98.21 \%$ for the 500-sample length of HRV signals. Our system yielded a sensitivity of $97.95 \%$, specificity of $98.07 \%$ and accuracy of $98.01 \%$ for HRV signals of a length of 1000 samples and a sensitivity of $97.76 \%$, specificity of $97.67 \%$ and accuracy of $97.71 \%$ for signals corresponding to the 2000-sample length of HRV signals. Our automated system can aid clinicians in the accurate detection of CHF using HRV signals. It can be installed in hospitals, polyclinics and remote villages where there is no access to cardiologists.
\end{abstract}

Keywords: CHF; HRV; FAWT; accumulated entropy; classifier

\section{Introduction}

Around the world, nearly 26 million people are living with Congestive Heart Failure (CHF) [1]. It is a pathophysiological condition in which heart is unable to provide sufficient blood supply to fulfill the requirements of the body [2]. It may be the result of structural or functional cardiac disorders. These disorders reduce the blood pumping ability of ventricles [3]. Dyspnea, edema and fatigue are the common symptoms of CHF [2,3]. It is the last stage of several cardiac diseases namely; heart valve disease, Myocardial Infarction (MI) and dilated cardiomyopathy [4]. In many cases, CHF is not discernible. Moreover, CHF patients are more susceptible to sudden cardiac 
death [5]. Therefore, CHF must be diagnosed at an early stage. In this work, our aim is to develop such a system that can automatically distinguish the normal persons and CHF patients using Heart Rate Variability (HRV) signals.

HRV signals may carry useful information related to the nature of heart disease and are extracted from the Electrocardiogram (ECG) signals [6]. This is computed by noting the time interval between two consecutive R-peaks [6]. Visual detection of the variations present in these HRV signals can be a tedious work, and there is a possibility of the inaccurate classification of diseased and normal signals. Therefore, several studies have been carried out for automated detection of normal and abnormal HRV signals. Signal analysis techniques such as Empirical Mode Decomposition (EMD) and Discrete Wavelet Transform (DWT) are found useful to gather information from HRV signals [7,8]. These signals have been widely used for diagnosing heart diseases. In [8,9], HRV signals are used to automatically diagnose Coronary Artery Disease (CAD). Moreover, HRV signals are used to analyze arrhythmia subjects [10] and for the risk prediction of cardiovascular diseases [11]. HRV signals of post MI patients are studied in [12]. These signals are also studied to investigate hypertension patients [13] and patients who are at the risk for sudden cardiac death [14]. These signals are also found useful in the detection of diabetes [15-17].

In [18], time domain analysis of HRV signals is performed, and it is concluded that CHF has an association with autonomic dysfunction. In [19], frequency domain parameters, namely Very Low Frequency (VLF), Low Frequency (LF), High Frequency (HF), total power and the ratio of LF to HF powers, are computed from the HRV signals. The VLF power is found to be an independent risk predictor in CHF patients. Depressed HRV is observed in CHF patients as compared to healthy persons [20]. In [21], the standard deviation of normal to normal beat intervals has shown the largest discrimination ability for normal and CHF subjects among nine long-term HRV measures. Significantly lower values of the normalized power of the LF component are observed in CHF patients [22]. Low Risk Patients (LRP) and High Risk Patients (HRP) of CHF are analyzed using HRV signals [23]. Frequency domain parameters computed from HRV signals are found depressed in HRPs, except LF/HF. In [24], the authors have studied HRV in CHF subjects and observed lower values of standard HRV measures, except HF power. The low values of HRV parameters have a correlation with the functional severity of heart failure [24].

HRV signals exhibit a nonlinear and non-stationary nature [6]. Hence, the analysis of HRV signals using linear methods and features may miss useful information. In [25], the analysis of the nonlinear properties of HRV gives independent information in the risk stratification of patients with CHF. In [26], complex Poincare plots are observed for the CHF patients. In [27], linear and non-linear features are used to discriminate the LRP and HRP of CHF disease. The discrimination ability of non-linear features is found to be better than linear features. Various nonlinear features, such as Detrended Fluctuation Analysis (DFA) [4], approximate entropy [28] and sample entropy [28], are found to be effective in the analysis of CHF HRV signals.

In this work, we have analyzed the HRV signals of the CHF and normal subjects for three different signal lengths at different frequency scales. The Flexible Analytic Wavelet Transform (FAWT) $[29,30]$ is used to decompose the HRV signals up to the fifth level of decomposition. Decomposed sub-band signals are used to obtain different frequency scales of HRV signals. Accumulated Fuzzy Entropy (AFEnt) and Accumulated Permutation Entropy (APEnt) are computed from the signals at different frequency scales to measure the complexity of HRV signals at different frequency scales. A total of 10 different frequency scales are obtained in which five frequency scales are obtained by adding the lower frequency sub-band signals into the higher frequency sub-band signal, and the other five are obtained by adding the higher frequency sub-band signals into the lower frequency sub-band signal. Finally, the obtained features are ranked using the Bhattacharyya ranking method [31] and fed to the Least Squares Support Vector Machine (LS-SVM) classifier [32]. The steps followed in our work can be seen in Figure 1. 
The remaining part of the paper is organized as follows: Section 2 describes the HRV dataset used in the present work, the segmentation of the HRV dataset, FAWT-based accumulated entropies, the ranking method and classification. Section 3 and Section 4 present the obtained results and discussion part, respectively. Finally, the present work is concluded in Section 5.

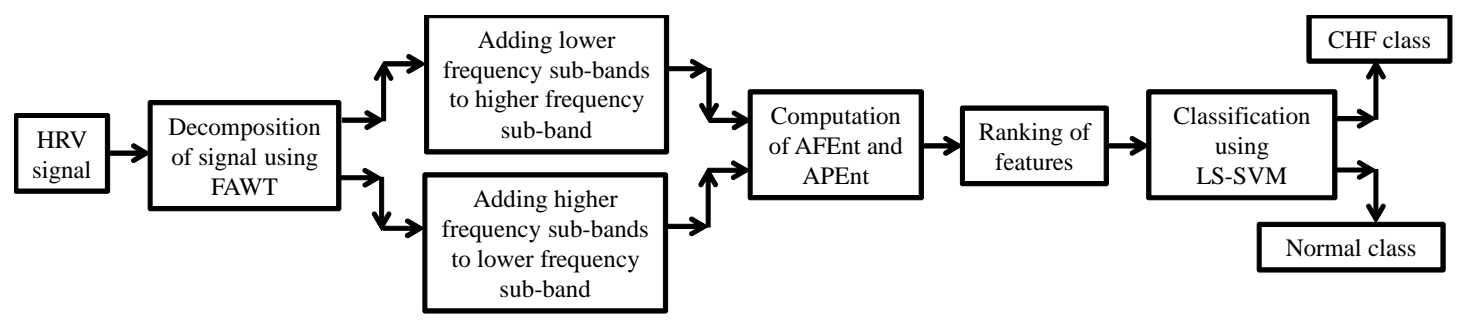

Figure 1. The proposed automatic diagnosis system for CHF using HRV signals.

\section{Methodology}

\subsection{HRV Dataset}

In this work, we have used online available databases for $\mathrm{CHF}$ and normal subjects. For CHF patients, the BIDMC CHF dataset [33,34] from PhysioBank (https://physionet.org/physiobank/ database/chfdb/) is used. The HRV signals of 15 CHF patients (11 males and 4 females) are used in this study. The age of the patients varies from 22 to 71 years for male subjects and from 54 to 63 years for female subjects. For normal subjects, two different datasets, MIT-BIH Normal Sinus Rhythm (NSR) [34] and Fantasia [34,35] from PhysioBank, are used. From the MIT-BIH NSR dataset (https://physionet.org/physiobank/database/nsrdb/), we have obtained HRV signals of 18 subjects (5 males and 13 females). The age of male subjects ranges from 26 to 45 years, and for female subjects, age varies in between 20 and 50 years. From the Fantasia dataset (https:/ / physionet.org/ physiobank/database/fantasia/), the HRV records of 40 subjects (20 young and 20 old) are obtained. The age variation of young subjects is 21 to 34 years, and for old subjects, it varies from 68 to 85 years. Information on RR-intervals is provided in text format in the PhysioBank. We have obtained RR-intervals directly from the PhysioNet. In this work, we did not eliminate the ectopic beats before the analysis. HRV signals are not resampled before the analysis.

\subsection{Segmentation of HRV Signals}

We have segmented the HRV signals into three different signal lengths: 500, 1000 and 2000 samples. Table 1 summarizes the number of HRV segments used for each signal length (500, 1000 and 2000 samples) in two classes. Plots of normal (MIT-BIH NSR dataset) and CHF (BIDMC dataset) HRV signals for 500 samples length are shown in Figure 2.

Table 1. Total number of extracted segments for various signal lengths.

\begin{tabular}{cccc}
\hline \multirow{2}{*}{ Database } & \multicolumn{3}{c}{ Total Segments } \\
\cline { 2 - 4 } & Signal Length $=\mathbf{5 0 0}$ Samples & Signal Length $=\mathbf{1 0 0 0}$ Samples & Signal Length = 2000 Samples \\
\hline CHF/BIDMC & 3212 & 1606 & 803 \\
Normal/MIT-BIH & 3420 & 1710 & 855 \\
Normal/Fantasia & 500 & 250 & 125 \\
\hline
\end{tabular}




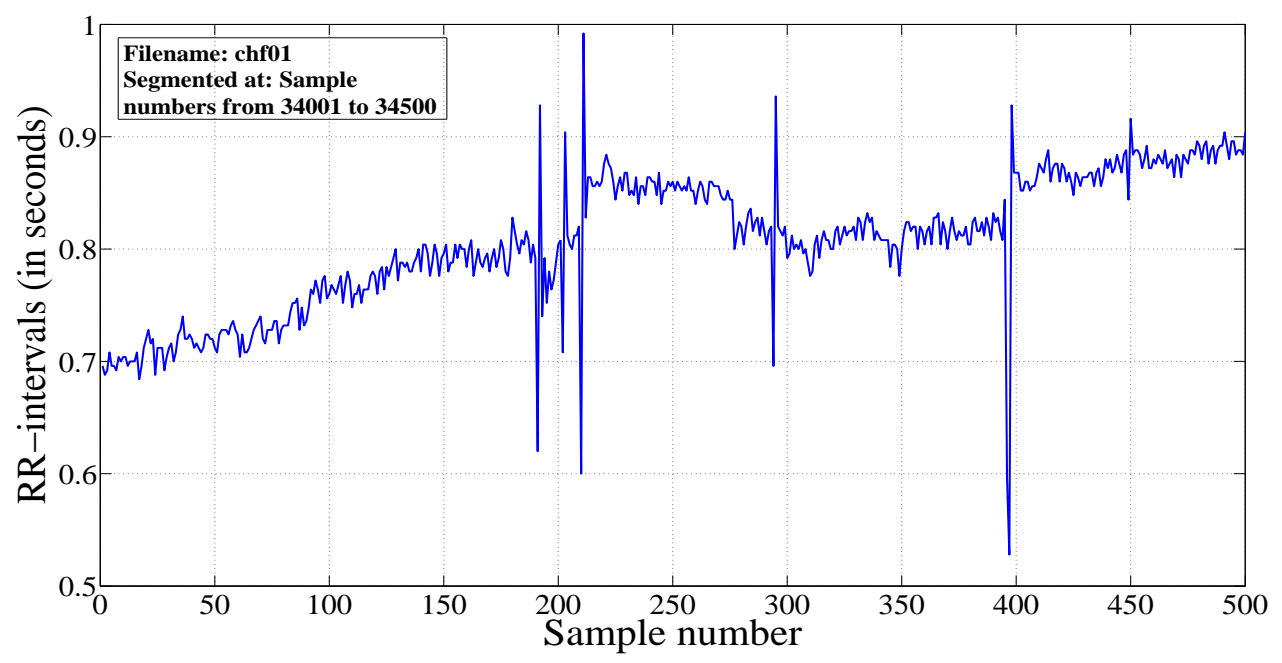

(a)

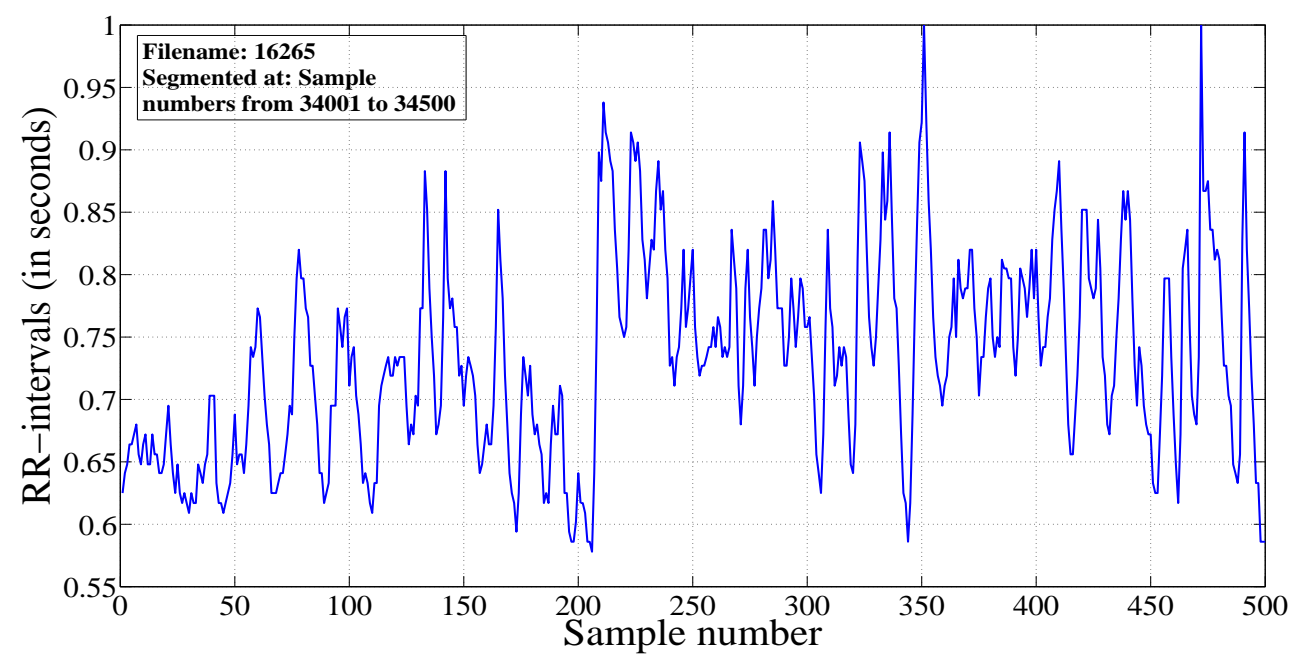

(b)

Figure 2. Plots of HRV signals of a 500-sample length: (a) CHF subject and (b) normal subject.

\subsection{Features Studied in This Work}

Nonlinear features are found suitable for analysis of the HRV signals [6]. Therefore, nonlinear parameters, namely AFEnt and APEnt, are proposed as features to classify the CHF and normal HRV signals in this work. A brief explanation of these parameters is provided in the following sections:

\subsubsection{Permutation Entropy}

This measures the complexity of HRV signals, which is determined by comparing the permutation patterns present in the samples of the signal [36]. Its computation depends on sequence length $e$ and delay time $\tau$. A total number of $e$ ! permutations is possible for the selected value of $e$. If the probability of occurrence of the $k$-th permutation pattern is denoted by $B_{k}$, then the Permutation Entropy (PEnt) can be computed as [36,37]:

$$
\text { PEnt }=-\sum_{k=1}^{e !} B_{k} \log \left(B_{k}\right)
$$

We have used this entropy due to its simplicity and robustness towards noise [37,38]. 


\subsubsection{Fuzzy Entropy}

The computation of Fuzzy Entropy (FEnt) measures the similarity that occurs in a HRV signal. For the computation of the FEnt, the following steps have to be performed [39]:

1. First, the sequences of length $e$ are extracted from the HRV signal.

2. Computation of the similarity degree $S_{j k}^{e}$ between two sequences ( $j$-th and $k$-th) using the fuzzy function [39] as follows:

$$
S_{j k}^{e}=\mu\left(s_{j k}^{e}, f, g\right)
$$

where $\mu, f$ and $g$ represent the fuzzy function, the gradient and the width of the fuzzy similarity boundary, respectively and $s_{j k}^{e}$ is the maximum absolute difference of the two sequence lengths.

3. Computation of $\varphi^{e}(f, g)$ as follows [39]:

$$
\varphi^{e}(f, g)=\frac{1}{P-e} \sum_{j=1}^{P-e} \frac{1}{P-e-1}\left[\sum_{k=1, k \neq j}^{P-e}\left(S_{j k}^{e}\right)\right]
$$

where $P$ denotes the total number of samples present in the HRV signal.

4. Finally, the FEnt can be computed as follows [39]:

$$
\operatorname{FEnt}(e, f, g, P)=\ln \left[\varphi^{e}(f, g)\right]-\ln \left[\varphi^{e+1}(f, g)\right]
$$

FEnt measures the similarity using exponential function, and Approximate Entropy (AEnt) and Sample Entropy (SEnt) measure the similarity using a tolerance limit [39]. Thus, FEnt uses the soft boundary for similarity measurement, and AEnt and SEnt use the hard boundary for similarity measurement. The hard boundary introduces discontinuity, which may abruptly change the entropy values with slight changes in the tolerance limit [39]. In our work, $f=2, g=0.2$ [39] are selected. In recent studies, FEnt is used in automated diagnosis of CAD [40].

\subsubsection{FAWT-Based Accumulated Entropies}

FAWT has an interesting property of analyzing the positive and negative frequencies separately using two high-pass channels in its Iterative Filter Bank (IFB) [29]. It also has a low-pass channel to analyze the low frequencies in its IFB. Separation of positive and negative frequencies allows one to select sampling rates arbitrarily in high-pass channels. This property makes the FAWT flexible by allowing one to control the $Q$-factor, dilation factor and redundancy [29]. This feature is not available in DWT. Moreover, the wavelet bases of FAWT are obtained in Hilbert transform pairs due to the separation of positive and negative frequencies [29].

The low-pass filter can be represented by the following mathematical equations [29]:

$$
H(w)= \begin{cases}(m n)^{1 / 2}, & |w|<w_{p} \\ (m n)^{1 / 2} \theta\left(\frac{w-w_{p}}{w_{s}-w_{p}}\right), & w_{p} \leq w \leq w_{s} \\ (m n)^{1 / 2} \theta\left(\frac{\pi-w_{p}+w_{p}}{w_{s}-w_{p}}\right), & -w_{s} \leq w \leq-w_{p} \\ 0, & |w| \geq w_{s}\end{cases}
$$

where $m$ and $n$ are the parameters that control the sampling rate of the low-pass channel. The $w_{s}$ and $w_{p}$ denote the stop band and pass band frequencies of the low-pass filter and can be defined as [29]: $w_{p}=\frac{(1-\beta) \pi}{m}+\frac{\epsilon}{m}, w_{s}=\frac{\pi}{n}$, 
The other used filter is the high-pass filter and can be expressed mathematically as follows [29]:

$$
G(w)= \begin{cases}(2 u v)^{1 / 2} \theta\left(\frac{\pi-w-w_{0}}{w_{1}-w_{0}}\right), & w_{0} \leq w<w_{1} \\ (2 u v)^{1 / 2}, & w_{1} \leq w<w_{2} \\ (2 u v)^{1 / 2} \theta\left(\frac{w-w_{2}}{w_{3}-w_{2}}\right), & w_{2} \leq w \leq w_{3} \\ 0, & w \in\left[0, w_{0}\right) \cup\left(w_{3}, 2 \pi\right)\end{cases}
$$

where parameters in FAWT $u$ and $v$ control the sampling rate of high-pass channels.

The other parameters are defined as follows [29]: $w_{0}=\frac{(1-\beta) \pi+\epsilon}{u}, w_{1}=\frac{m \pi}{n u}$ and:

$$
w_{2}=\frac{\pi-\epsilon}{u}, w_{3}=\frac{\pi+\epsilon}{u}, \epsilon \leq \frac{m-n+\beta n}{m+n} \pi .
$$

The $\theta(w)$ can be given by the following expression [29,41]:

$$
\theta(w)=\frac{[2-\cos (w)]^{1 / 2}[1+\cos (w)]}{2} \text { for } w \in[0, \pi]
$$

The perfect reconstruction filter bank in FAWT framework can be implemented by satisfying the following condition [29]:

$$
\begin{gathered}
|\theta(\pi-w)|^{2}+|\theta(w)|^{2}=1 \\
\left(1-\frac{m}{n}\right) \leq \beta \leq\left(\frac{u}{v}\right)
\end{gathered}
$$

Here, $\beta$ is another parameter and related to the $Q$-factor as follows $Q=\frac{2-\beta}{\beta}$. Redundancy is defined as the ratio of output samples to the input samples and can be expressed as [29]:

$$
R=\left(\frac{u}{v}\right) \frac{1}{1-(m / n)}
$$

The values of the parameters used in the present work are $m=5, n=6, u=1, v=2$ and $\beta=(0.8 u) / v[30,40,42]$. The 5th level FAWT-based decomposition of signals in Figure 2 is shown in Figure 3. These figures are shown from the highest frequency sub-band signal to the lowest one. $A_{5}$ represents the approximation signal with a lower frequency components than $D_{1}$ to $D_{5}$. FAWT has been used to detect CAD automatically in [40,42] and to find faults in rotating machinery [30]. For implementation of FAWT, we have used the Matlab toolbox provided at http:/ / web.itu.edu.tr/ ibayram/AnDWT/.

APEnt and AFEnt can be computed over cumulative sums of sub-band signals obtained by the decomposition of HRV signals using the FAWT method.

The APEnt can be defined as:

$$
\operatorname{APEnt}(i, e, \tau)=\operatorname{PEnt}\left[S_{\text {sub-bands }}^{i}, e, \tau\right]
$$

The AFEnt can be defined as follows:

$$
\operatorname{AFEnt}(i, e, f, g, P)=\operatorname{FEnt}\left[S_{\text {sub-bands }}^{i}, e, f, g, P\right]
$$

where $S_{\text {sub-bands }}^{i}$ can be expressed as:

$$
S_{\text {sub-bands }}^{i}=\mathrm{SL}_{i}, \quad i=1,2, . ., J
$$

when sub-band signals are combined from lower frequency to higher frequency. 


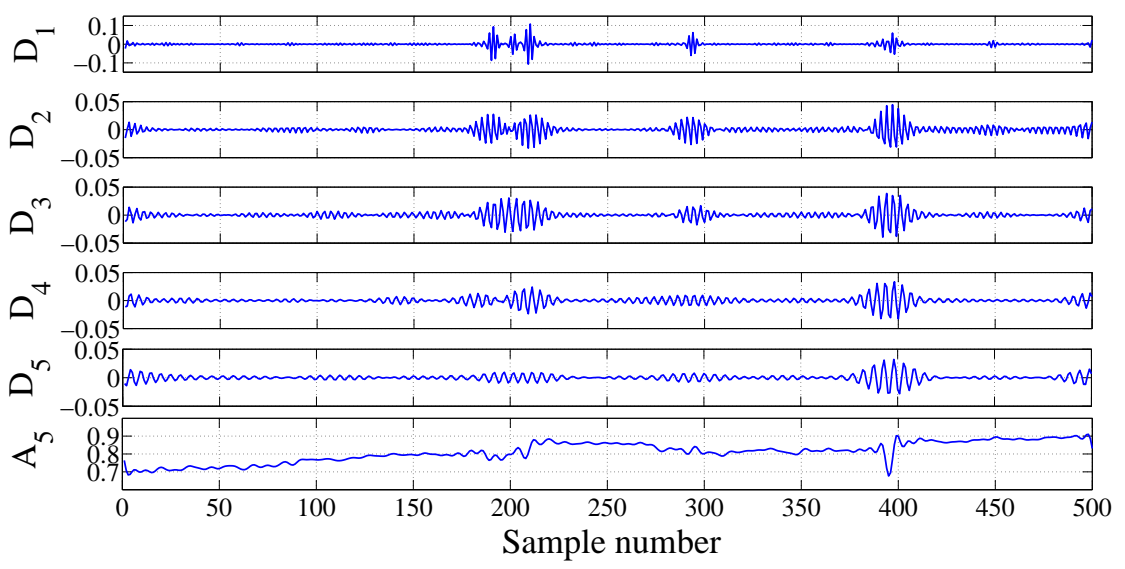

(a)

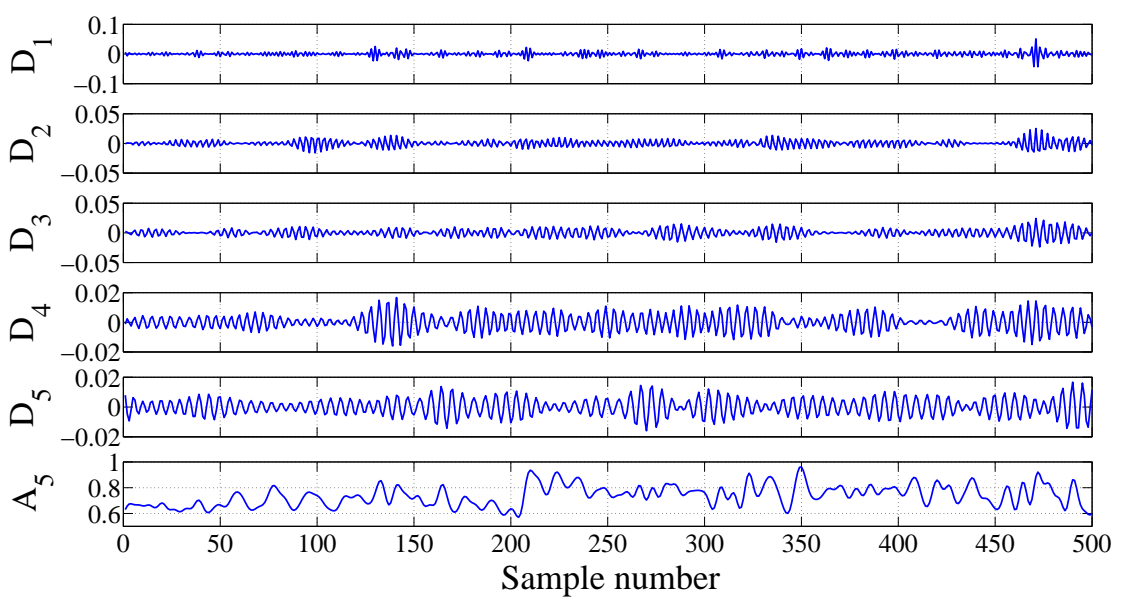

(b)

Figure 3. Decomposition of HRV signals using the FAWT method: (a) CHF subject and (b) normal subject.

For the combination of sub-band signals from higher frequency to lower frequency, $S_{\text {sub-bands }}^{i}$ can be given as:

$$
S_{\text {sub-bands }}^{i}=\mathrm{SH}_{i}, \quad i=1,2, . ., J
$$

We have selected $\tau=2$ in our work to compute the APEnt. In (13) and (14), J represents the decomposition level, which is selected as 5 in the present work. A total of 5 detail sub-band signals $\left(D_{1}\right.$ to $\left.D_{5}\right)$ and the approximation signal $\left(A_{5}\right)$ are used to obtain different frequency scales. The frequency scaled sub-band signals are shown in Figures 4 and 5 for CHF and normal subjects corresponding to a 500-sample length of the HRV signal. Information related to combination of sub-band signals is provided in Table 2. In [43], intrinsic mode functions obtained from the EMD method are utilized in combination from low to high frequency and high to low frequency for analyzing the postural time series.

Table 2. Signals at different frequency scales and the combination of used sub-band signals.

\begin{tabular}{cccc}
\hline $\begin{array}{c}\text { Signals at Different } \\
\text { Frequency Scales }\end{array}$ & $\begin{array}{c}\text { Accumulation of } \\
\text { Sub-Band Signals }\end{array}$ & $\begin{array}{c}\text { Signals at Different } \\
\text { Frequency Scales }\end{array}$ & $\begin{array}{c}\text { Accumulation of } \\
\text { Sub-Band Signals }\end{array}$ \\
\hline $\mathrm{SL}_{1}$ & $\mathrm{~A}_{5}$ & $\mathrm{SH}_{1}$ & $\mathrm{D}_{1}$ \\
$\mathrm{SL}_{2}$ & $\mathrm{~A}_{5}+\mathrm{D}_{5}$ & $\mathrm{SH}_{2}$ & $\mathrm{D}_{1}+\mathrm{D}_{2}$ \\
$\mathrm{SL}_{3}$ & $\mathrm{~A}_{5}+\mathrm{D}_{5}+\mathrm{D}_{4}$ & $\mathrm{SH}_{3}$ & $\mathrm{D}_{1}+\mathrm{D}_{2}+\mathrm{D}_{3}$ \\
$\mathrm{SL}_{4}$ & $\mathrm{~A}_{5}+\mathrm{D}_{5}+\mathrm{D}_{4}+\mathrm{D}_{3}$ & $\mathrm{SH}_{4}$ & $\mathrm{D}_{1}+\mathrm{D}_{2}+\mathrm{D}_{3}+\mathrm{D}_{4}$ \\
$\mathrm{SL}_{5}$ & $\mathrm{~A}_{5}+\mathrm{D}_{5}+\mathrm{D}_{4}+\mathrm{D}_{3}+\mathrm{D}_{2}$ & $\mathrm{SH}_{5}$ & $\mathrm{D}_{1}+\mathrm{D}_{2}+\mathrm{D}_{3}+\mathrm{D}_{4}+\mathrm{D}_{5}$ \\
\hline
\end{tabular}




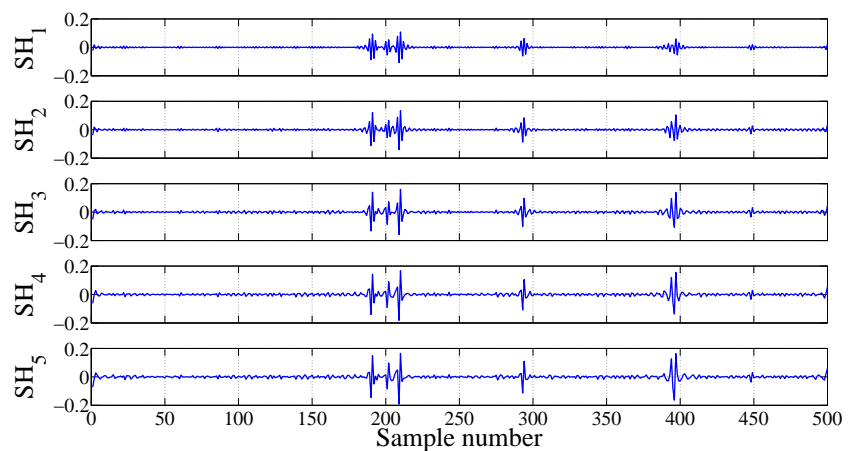

(a)

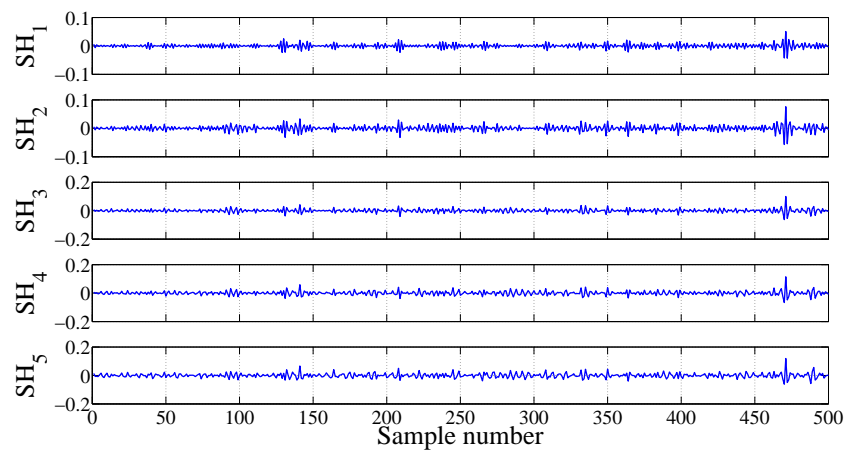

(b)

Figure 4. Plots of HRV signals at various frequency scales (the first subplot represents the highest frequency sub-band signal, and remaining subplots are the addition of the lower frequency sub-band signals to the higher frequency sub-band signal): (a) CHF subject and (b) normal subject.

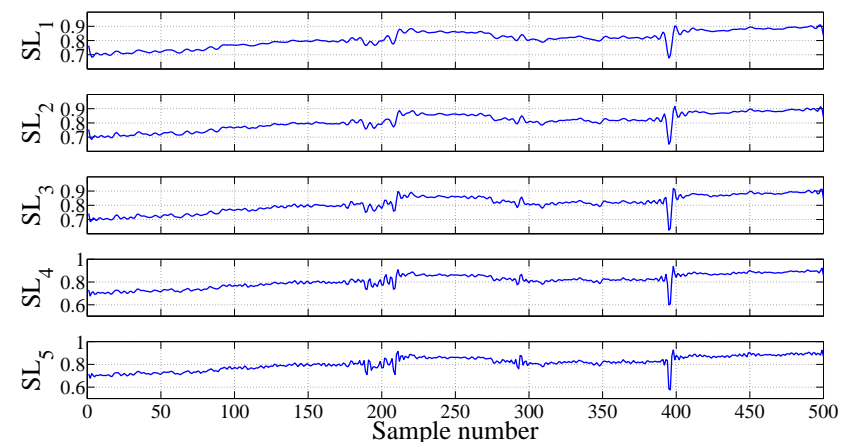

(a)

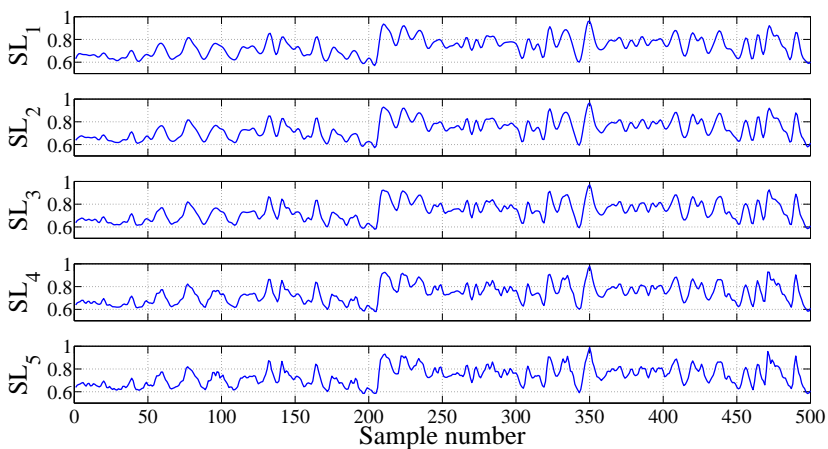

(b)

Figure 5. Plots of HRV signals at various frequency scales (the first subplot represents the lowest frequency sub-band signal, and remaining subplots are the addition of the higher frequency sub-band signals to the lower frequency sub-band signal): (a) CHF subject and (b) normal subject. 


\subsection{Ranking and Classification}

Ranking methods are used to arrange features from higher discrimination ability to lower discrimination ability, and higher rank features can be selected to reduce the complexity without degrading the performance of the classifier [44]. In our work, the features are ranked using Bhattacharyya ranking method [31]. It is based on the Bhattacharyya distance to measure the discrimination ability of features in separating two classes [31]. These ranked features are applied to the LS-SVM classifier. It is the least square implementation of Support Vector Machine (SVM). In the SVM approach, a hyperplane is constructed in higher dimensional space for data separation corresponding to different classes [32]. The LS-SVM-based automated decision mathematically can be expressed as follows [32,45]:

$$
V=\operatorname{sign}\left[\sum_{m=1}^{M} \alpha_{m} w_{m} L\left(y, y_{m}\right)+b\right]
$$

In the above expression, $L\left(y, y_{m}\right)$ and $\alpha_{m}$ denote a kernel function and Lagrangian multiplier, respectively, and $y_{m}$ is the $m$-th input vector, which has $D$-dimensions; $b$ denotes the bias term; and $w_{m}$ is the target vector and $M$ denotes the total number of data points. In the present work, the linear kernel, Radial Basis Function (RBF), polynomial and Morlet wavelet are selected as the kernel function of the LS-SVM classifier.

The mathematical expression of the linear kernel is given as [32]:

$$
L\left(y, y_{m}\right)=y_{m}^{T} y
$$

The RBF kernel in a mathematical way can be represented by the following expression [46]:

$$
L\left(y, y_{m}\right)=e^{\frac{-\left\|y-y_{m}\right\|^{2}}{2 \sigma^{2}}}
$$

In (17), the parameter $\sigma$ controls the width of the RBF kernel function.

For the polynomial kernel function, the mathematical expression can be given as [32]:

$$
L\left(y, y_{m}\right)=\left(y_{m}^{T} y+1\right)^{r}
$$

where $r$ is the order of the polynomial kernel.

The Morlet wavelet kernel can be defined by the following mathematical expression $[47,48]$ :

$$
L\left(y, y_{m}\right)=\prod_{n=1}^{D} \cos \left[z_{0} \frac{y^{n}-y_{m}^{n}}{l}\right] e^{\frac{-\left\|y^{n}-y_{m}^{n}\right\|^{2}}{2 l^{2}}}
$$

where $l$ represents the scale factor of the Morlet wavelet kernel and $D$ denotes the dimension of the feature set. In the present work, the classification performance measures, namely specificity, sensitivity and Accuracy (ACC) [49], are computed to determine the effectiveness of the classifier. We have used the svmtrain and svmclassify MATLAB functions to train and test the classifier.

\section{Results}

In the present work, we have computed APEnt and AFEnt at different frequency scales. These different frequency scales of HRV signals are obtained by adding the sub-band signal from the high frequency component to the low frequency component and the low frequency component to the high frequency component. These sub-band signals are obtained from FAWT-based decomposition. We have analyzed HRV signals for three signal lengths, 500, 1000 and 2000 samples. The obtained results for these three different lengths of HRV signals are as follows: 


\subsection{Results with a Signal Length of 500 Samples}

We have one dataset for CHF patients (BIDMC) and two datasets of normal subjects (Fantasia dataset and MIT-BIH NSR dataset). The HRV signals of two classes (normal and CHF) are subjected to FAWT-based decomposition. The signals are decomposed up to the fifth level. We have made four different combinations of datasets, namely; Unbalanced Dataset 1 (UD 1), Unbalanced Dataset 2 (UD 2), Balanced Dataset 1 (BD 1) and Balanced Dataset 2 (BD 2).

\subsubsection{Results for Unbalanced Dataset 1}

This dataset has the recordings of MIT-BIH NSR for normal subjects and the BIDMC dataset for CHF patients. This is the largest dataset among the four combination of datasets used in the present work. This selected dataset has 3420 normal segments and 3212 CHF segments of HRV signals. To find the suitable sequence length for AFEnt and APEnt, we have computed the classification accuracy at various sequence lengths for AFEnt and APEnt using the LS-SVM classifier. Classification accuracy for various sequence lengths can be seen in Table 3 for AFEnt and APEnt. From Table 3, we can observed that AFEnt and APEnt show better performance for sequence length $(e)$ three and four, respectively. For AFEnt and APEnt, the highest classification accuracy of $96.29 \%$ and $91.39 \%$ using Morlet wavelet kernel is obtained respectively. For further analysis, we have used sequence length three for AFEnt and sequence length four for APEnt.

Mean and Standard Deviation (SD) values of AFEnt for sequence length three and APEnt for sequence length four can be seen in Table 4. We have also computed $p$-values using the Kruskal-Wallis test [50] to check the statistical significance of the features in order to discriminate normal and CHF HRV signals. This test recently has been used to check the discrimination ability of the features for analyzing the epileptic Electroencephalogram (EEG) signals [51-53]. We can observe in Table 4 that $p$-values are significantly low ( $p$-value $<0.05$ ) for all of the features. Further, we have applied the Bhattacharyya ranking method to rank the features. These ranked features can be seen in Table 5 . We can observe in Table 5 that AFEnt features achieve higher ranking as compared to APEnt features. In Table 5, the indices $\left(\mathrm{SH}_{1}\right.$ to $\mathrm{SH}_{5}$ and $\mathrm{SL}_{1}$ to $\left.\mathrm{SL}_{5}\right)$ represent the frequency-scaled signals from which AFEnt and APEnt are computed.

These ranked features are fed to the LS-SVM classifier by appending the next lower ranking features to the highest ranking feature up to 20 features. The accuracies of the ranked features with LS-SVM for different kernels (linear, RBF, polynomial and Morlet wavelet) are shown in Figure 6. It can be observed from Figure 6 that the LS-SVM classifier achieved the highest accuracy for Morlet wavelet kernel with the first 18 features, for the polynomial kernel with the first 17 features and for the RBF kernel with the first 14 features. The classification accuracy with the linear kernel is highest for 20 features. The classifier is trained and tested using the ten-fold cross-validation method [54], which was recently used in several studies for the training and testing of the classifier [55-57]. The best classification performance of LS-SVM in terms of specificity, sensitivity and accuracy for different kernels is provided in Table 6. The maximum value of accuracy can be seen from Table 6, which is $98.21 \%$ for Morlet wavelet kernel. 
Table 3. Classification performance for Unbalanced Dataset 1 (length of the signal = 500 samples) using Accumulated Fuzzy Entropy (AFEnt) and Accumulated Permutation entropy (APEnt) separately with LS-SVM for different sequence lengths and different kernel functions and parameters (entropies computed from all of the frequency scales are used for classification). ACC, Accuracy.

\begin{tabular}{|c|c|c|c|c|c|c|c|c|}
\hline \multirow{2}{*}{$\begin{array}{l}\text { Sequence } \\
\text { Length }\end{array}$} & \multicolumn{4}{|c|}{ AFEnt } & \multicolumn{4}{|c|}{ APEnt } \\
\hline & $\begin{array}{l}\text { ACC (\%) with } \\
\text { Linear Kernel }\end{array}$ & $\begin{array}{c}\text { ACC (\%) with RBF } \\
\text { Kernel }(\sigma=1)\end{array}$ & $\begin{array}{c}\text { ACC (\%) with Morlet Wavelet } \\
\text { Kernel }\left(l=1.6, z_{0}=0.25\right)\end{array}$ & $\begin{array}{c}\text { ACC (\%) with Polynomial } \\
\text { Kernel (Order = 3) }\end{array}$ & $\begin{array}{l}\text { ACC (\%) with } \\
\text { Linear Kernel }\end{array}$ & $\begin{array}{c}\text { ACC }(\%) \text { with RBF } \\
\text { Kernel }(\sigma=1)\end{array}$ & $\begin{array}{c}\text { ACC (\%) with Morlet Wavelet } \\
\text { Kernel }\left(l=5, z_{0}=0.25\right)\end{array}$ & $\begin{array}{c}\text { ACC (\%) with Polynomial } \\
\text { Kernel (Order = 3) } \\
\end{array}$ \\
\hline 3 & 90.66 & 95.67 & 96.29 & 95.02 & 82.62 & 89.32 & 89.17 & 88.16 \\
\hline 4 & 90.86 & 94.54 & 95.31 & 94.52 & 84.80 & 91.26 & 91.39 & 90.89 \\
\hline 5 & 89.77 & 94.90 & 95.98 & 94.43 & 84.84 & 90.65 & 90.65 & 90.75 \\
\hline 6 & 92.12 & 95.43 & 95.92 & 95.38 & 83.05 & 89.24 & 89.2 & 89.02 \\
\hline 7 & 91.36 & 94.84 & 95.55 & 94.79 & 78.69 & 85.93 & 86.17 & 85.20 \\
\hline
\end{tabular}

Table 4. Mean, SD and $p$-values of AFEnt and APEnt for Unbalanced Dataset 1 (length of the signal = 500 samples) at various frequency scales provided by FAWT-based decomposition applied to normal and CHF HRV signals.

\begin{tabular}{|c|c|c|c|c|c|c|c|c|c|c|c|c|}
\hline Entropy $\downarrow$ & Signals a & t Frequency Scales $\rightarrow$ & $\mathrm{SH}_{1}$ & $\mathrm{SH}_{2}$ & $\mathrm{SH}_{3}$ & $\mathrm{SH}_{4}$ & $\mathrm{SH}_{5}$ & $\mathrm{SL}_{5}$ & $\mathrm{SL}_{4}$ & $\mathrm{SL}_{3}$ & $\mathrm{SL}_{2}$ & $\mathrm{SL}_{1}$ \\
\hline \multirow{3}{*}{ AFEnt } & $\mathrm{Cl}$ & Mean \pm SD & $0.0132 \pm 0.0222$ & $0.0313 \pm 0.0420$ & $0.0447 \pm 0.0554$ & $0.0555 \pm 0.0654$ & $0.0610 \pm 0.0716$ & $0.0361 \pm 0.0467$ & $0.0342 \pm 0.0377$ & $0.0394 \pm 0.0397$ & $0.0361 \pm 0.0369$ & $0.0291 \pm 0.0296$ \\
\hline & Normal & Mean \pm SD & $0.0042 \pm 0.0085$ & $0.0268 \pm 0.0185$ & $0.0502 \pm 0.0317$ & $0.0694 \pm 0.0465$ & $0.0841 \pm 0.0565$ & $0.0702 \pm 0.0488$ & $0.0689 \pm 0.0476$ & $0.0683 \pm 0.0469$ & $0.0628 \pm 0.0425$ & $0.0568 \pm 0.0352$ \\
\hline & & value & $7.92 \times 10^{-85}$ & $5.63 \times 10^{-45}$ & $2.32 \times 10^{-161}$ & $7.37 \times 10^{-200}$ & $5.39 \times 10^{-273}$ & 0 & 0 & $9.49 \times 10^{-276}$ & $2.59 \times 10^{-273}$ & 0 \\
\hline \multirow{3}{*}{ APEnt } & $\mathrm{CHF}$ & $n \pm S D$ & $2.6932 \pm 0.0717$ & $3.0413 \pm 0.0870$ & $3.0829 \pm 0.0955$ & $3.0418 \pm 0.1221$ & $3.0393 \pm 0.1289$ & $3.0657 \pm 0.0950$ & $3.0442 \pm 0.0916$ & $3.0739 \pm 0.0790$ & $3.0360 \pm 0.1210$ & $2.8731 \pm 0.1484$ \\
\hline & Normal & Mean \pm SD & $2.6810 \pm 0.0581$ & $3.0708 \pm 0.0489$ & $3.0764 \pm 0.1191$ & $2.9902 \pm 0.1556$ & $2.9718 \pm 0.1591$ & $3.0192 \pm 0.1019$ & $2.9981 \pm 0.1070$ & $2.9524 \pm 0.1242$ & $2.8492 \pm 0.1513$ & $2.6972+0.1449$ \\
\hline & & value & $8.09 \times 10^{-16}$ & $1.81 \times 10^{-51}$ & $2.13 \times 10^{-9}$ & $2.75 \times 10^{-42}$ & $2.42 \times 10^{-81}$ & $5.52 \times 10^{-120}$ & $4.32 \times 10^{-85}$ & 0 & 0 & 0 \\
\hline
\end{tabular}

Table 5. Ranked features using the Bhattacharyya ranking method for Unbalanced Dataset 1 (signal length = 500 samples).

\begin{tabular}{|c|c|c|c|c|c|c|c|c|c|c|}
\hline $\begin{array}{l}\text { Feature Rank } \\
\text { Feature name }\end{array}$ & $\begin{array}{c}1 \\
\text { AFEnts } \\
\text { SH }_{1}\end{array}$ & $\begin{array}{c}2 \\
\text { AFEnt }\end{array}$ & $\begin{array}{c}3 \\
\text { APEnts } \\
\end{array}$ & $\begin{array}{c}4 \\
\text { APEntsL }_{3} \\
\end{array}$ & $\begin{array}{c}5 \\
\text { APEntsL } \\
\end{array}$ & $\begin{array}{c}\mathbf{6} \\
\text { APEnts } \mathrm{SH}_{2} \\
\end{array}$ & $\begin{array}{c}7 \\
\text { AFEnt } \\
\mathrm{SH}_{3} \\
\end{array}$ & $\begin{array}{c}8 \\
\text { AFEntsH }_{4} \\
\end{array}$ & $\begin{array}{c}9 \\
\text { AFEntsL }\end{array}$ & $\begin{array}{c}10 \\
\text { APEnts } \\
\end{array}$ \\
\hline $\begin{array}{c}\text { Feature Rank } \\
\text { Feature name }\end{array}$ & $\begin{array}{c}11 \\
\text { APEnt }_{\mathrm{SH}_{4}}\end{array}$ & $\begin{array}{c}12 \\
\text { AFEnt }_{S_{L_{1}}}\end{array}$ & $\begin{array}{c}13 \\
\text { AFEnt } \\
\mathrm{SH}_{5}\end{array}$ & $\begin{array}{c}\mathbf{1 4} \\
\text { APEnt }_{\mathrm{SL}_{4}}\end{array}$ & $\begin{array}{c}15 \\
\text { AFEnt }_{\mathrm{SL}_{3}}\end{array}$ & $\begin{array}{c}16 \\
\text { AFEnt }_{\mathrm{SL}_{2}}\end{array}$ & $\begin{array}{c}17 \\
\text { AFEnt }_{S_{5}}\end{array}$ & $\begin{array}{c}18 \\
\text { APEnt }_{\mathrm{SH}_{3}}\end{array}$ & $\begin{array}{c}19 \\
\text { APEnt }_{\mathrm{SH}_{1}}\end{array}$ & $\begin{array}{c}20 \\
\text { APEnt }_{\mathrm{SL}_{5}}\end{array}$ \\
\hline
\end{tabular}


Table 6. Classification performance of the LS-SVM classifier for various combinations of datasets (signal length $=500$ samples) with different kernel functions.

\begin{tabular}{|c|c|c|c|c|c|c|}
\hline $\begin{array}{l}\text { Combinations } \\
\text { of Datasets }\end{array}$ & Kernels & Kernel Parameters & $\begin{array}{l}\text { Number of } \\
\text { Features }\end{array}$ & Sensitivity (\%) & Specificity (\%) & $\operatorname{ACC}(\%)$ \\
\hline \multirow{4}{*}{$\begin{array}{l}\text { Unbalanced } \\
\text { Dataset } 1\end{array}$} & Morlet wavelet & \multirow{4}{*}{$\begin{array}{c}l=6.2, z_{0}=0.25 \\
\text { Order }=3 \\
\sigma=1\end{array}$} & 18 & 98.07 & 98.33 & 98.21 \\
\hline & Polynomial & & 17 & 97.76 & 97.72 & 97.74 \\
\hline & RBF & & 14 & 97.98 & 98.33 & 98.16 \\
\hline & Linear & & 20 & 90.26 & 93.74 & 92.05 \\
\hline \multirow{4}{*}{$\begin{array}{l}\text { Unbalanced } \\
\text { Dataset } 2\end{array}$} & Morlet wavelet & \multirow{4}{*}{$\begin{array}{c}l=7.9, z_{0}=0.25 \\
\text { Order }=3 \\
\sigma=1.2\end{array}$} & 20 & 97.85 & 93.80 & 97.31 \\
\hline & Polynomial & & 17 & 96.51 & 94.20 & 96.20 \\
\hline & RBF & & 19 & 97.95 & 93.40 & 97.33 \\
\hline & Linear & & 20 & 91.38 & 84.00 & 90.38 \\
\hline \multirow{4}{*}{$\begin{array}{l}\text { Balanced } \\
\text { Dataset } 1\end{array}$} & Morlet wavelet & \multirow{4}{*}{$\begin{array}{c}l=6.7, z_{0}=0.25 \\
\text { Order }=3 \\
\sigma=1\end{array}$} & 15 & 99.60 & 99.20 & 99.40 \\
\hline & Polynomial & & 11 & 99.00 & 97.80 & 98.40 \\
\hline & $\mathrm{RBF}$ & & 15 & 99.80 & 99.20 & 99.50 \\
\hline & Linear & & 18 & 96.00 & 97.20 & 96.60 \\
\hline \multirow{4}{*}{$\begin{array}{l}\text { Balanced } \\
\text { Dataset } 2\end{array}$} & Morlet wavelet & \multirow{4}{*}{$\begin{array}{c}l=7.7, z_{0}=0.25 \\
\text { Order }=3 \\
\sigma=1.2\end{array}$} & 16 & 97.60 & 97.80 & 97.70 \\
\hline & Polynomial & & 12 & 97.60 & 96.40 & 97.00 \\
\hline & RBF & & 16 & 97.60 & 98.00 & 97.80 \\
\hline & Linear & & 20 & 93.60 & 90.20 & 91.90 \\
\hline
\end{tabular}

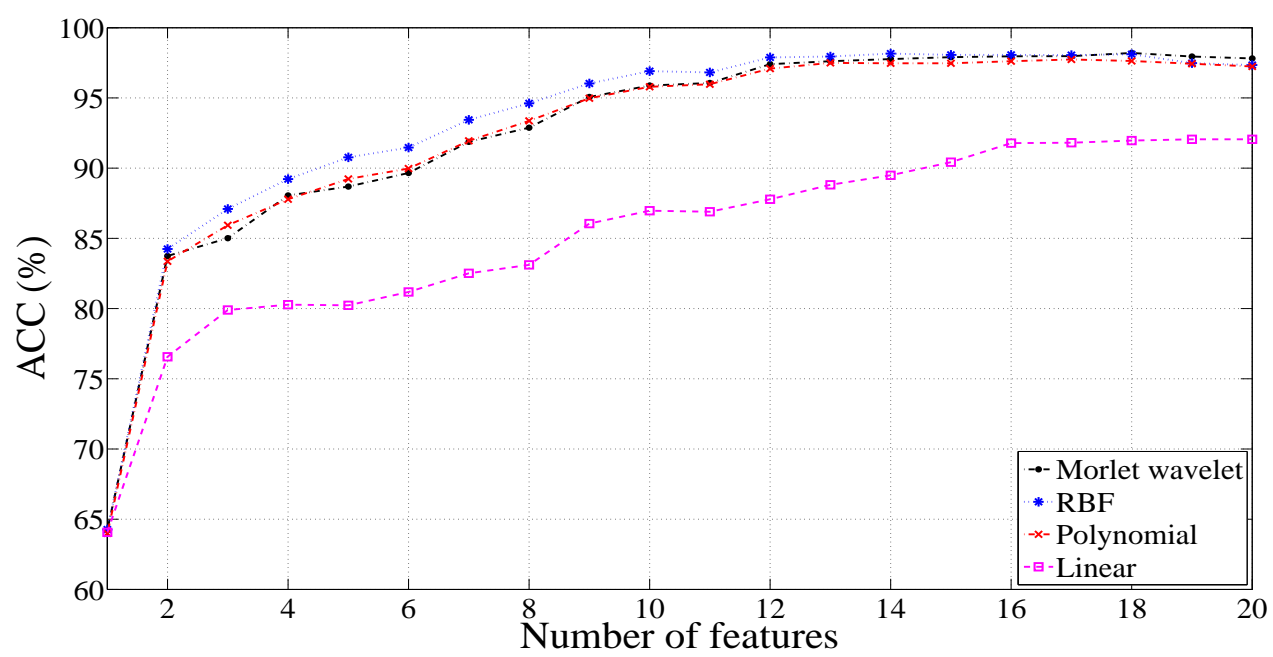

Figure 6. Plot of the classification accuracies versus the number of features for Unbalanced Dataset 1 (length of the signal $=500$ samples).

\subsubsection{Results for Unbalanced Dataset 2}

This dataset includes the HRV signals from Fantasia (normal subject) and the BIDMC dataset (CHF patients). This dataset has 500 segments of normal and 3212 segments of CHF HRV signals. The $p$-values, mean and SD values of AFEnt and APEnt are given in Table 7.

We can observe from Table 7 that $p$-values are significantly low ( $p$-value $<0.05)$ for all of the features, except AFEnt for $\mathrm{SH}_{1}$ and APEnt for $\mathrm{SL}_{5}$ and $\mathrm{SL}_{4}$. The classification accuracy of the LS-SVM classifier for the ranked features with the different kernels used in this work is shown in Figure 7. For RBF, polynomial and Morlet wavelet kernels, the highest accuracy of classification is $97.33 \%$ with 19 features, $96.20 \%$ with 17 features and $97.31 \%$ with 20 features, respectively. For linear kernel, maximum classification accuracy is $90.38 \%$ from 20 features. The remaining classification parameters (specificity and sensitivity) are given in Table 6. 
Table 7. Mean, SD, $p$-values of AFEnt and APEnt for Unbalanced Dataset 2 (length of the signal = 500 samples) at various frequency scales provided by FAWT-based decomposition applied to HRV signals of CHF patients and normal subjects.

\begin{tabular}{|c|c|c|c|c|c|c|c|c|c|c|c|c|}
\hline Entropy $\downarrow$ & Signals a & th Frequency Scales $\rightarrow$ & $\mathrm{SH}_{1}$ & $\mathrm{SH}_{2}$ & $\mathrm{SH}_{3}$ & $\mathrm{SH}_{4}$ & $\mathrm{SH}_{5}$ & $\mathrm{SL}_{5}$ & $\mathrm{SL}_{4}$ & $\mathrm{SL}_{3}$ & $\mathrm{SL}_{2}$ & $\mathrm{SL}_{1}$ \\
\hline \multirow{3}{*}{ AFEnt } & $\mathrm{CF}$ & Mean & $0.0132 \pm 0.0222$ & $0.0313 \pm 0.0420$ & $0.0447 \pm 0.0554$ & $0.0555 \pm 0.0654$ & $0.0610 \pm 0.0716$ & $0.0361 \pm 0.0467$ & $0.0342 \pm 0.0377$ & $0.0394 \pm 0.0397$ & $0.0361 \pm 0.0369$ & $0.0291 \pm 0.0296$ \\
\hline & Normal & Mean \pm SD & $0.0117 \pm 0.0192$ & $0.0377 \pm 0.0323$ & $0.0622 \pm 0.0474$ & $0.0807 \pm 0.0577$ & $0.0931 \pm 0.0640$ & $0.0824 \pm 0.0533$ & $0.0796 \pm 0.0509$ & $0.0792 \pm 0.0504$ & $0.0740 \pm 0.0470$ & $0.0659 \pm 0.0404$ \\
\hline & & value & 0.6866 & $2.50 \times 10^{-30}$ & $5.93 \times 10^{-52}$ & $3.37 \times 10^{-58}$ & $3.06 \times 10^{-65}$ & $3.65 \times 10^{-125}$ & $5.82 \times 10^{-116}$ & $4.04 \times 10^{-88}$ & $9.86 \times 10^{-91}$ & $1.41 \times 10^{-106}$ \\
\hline \multirow{3}{*}{ APEnt } & & Mean $\pm \mathrm{SD}$ & $2.6932 \pm 0.0717$ & $3.0413 \pm 0.0870$ & $3.0829 \pm 0.0955$ & $3.0418 \pm 0.1221$ & $3.0393 \pm 0.1289$ & $3.0657 \pm 0.0950$ & $3.0442 \pm 0.0916$ & $3.0739 \pm 0.0790$ & $3.0360 \pm 0.1210$ & $2.8731 \pm 0.1484$ \\
\hline & Normal & Mean \pm SD & $2.7088 \pm 0.0721$ & $3.0672 \pm 0.0687$ & $3.0387 \pm 0.0947$ & $2.9600 \pm 0.1397$ & $2.9510 \pm 0.1405$ & $3.0563 \pm 0.1104$ & $3.0304 \pm 0.1205$ & $2.9953 \pm 0.1397$ & $2.8926 \pm 0.1602$ & $2.7450 \pm 0.1437$ \\
\hline & & value & $4.15 \times 10^{-7}$ & $3.17 \times 10^{-18}$ & $2.41 \times 10^{-34}$ & $6.25 \times 10^{-45}$ & $8.31 \times 10^{-51}$ & 0.296 & 0.255 & $6.43 \times 10^{-42}$ & $5.69 \times 10^{-99}$ & $1.21 \times 10^{-74}$ \\
\hline
\end{tabular}

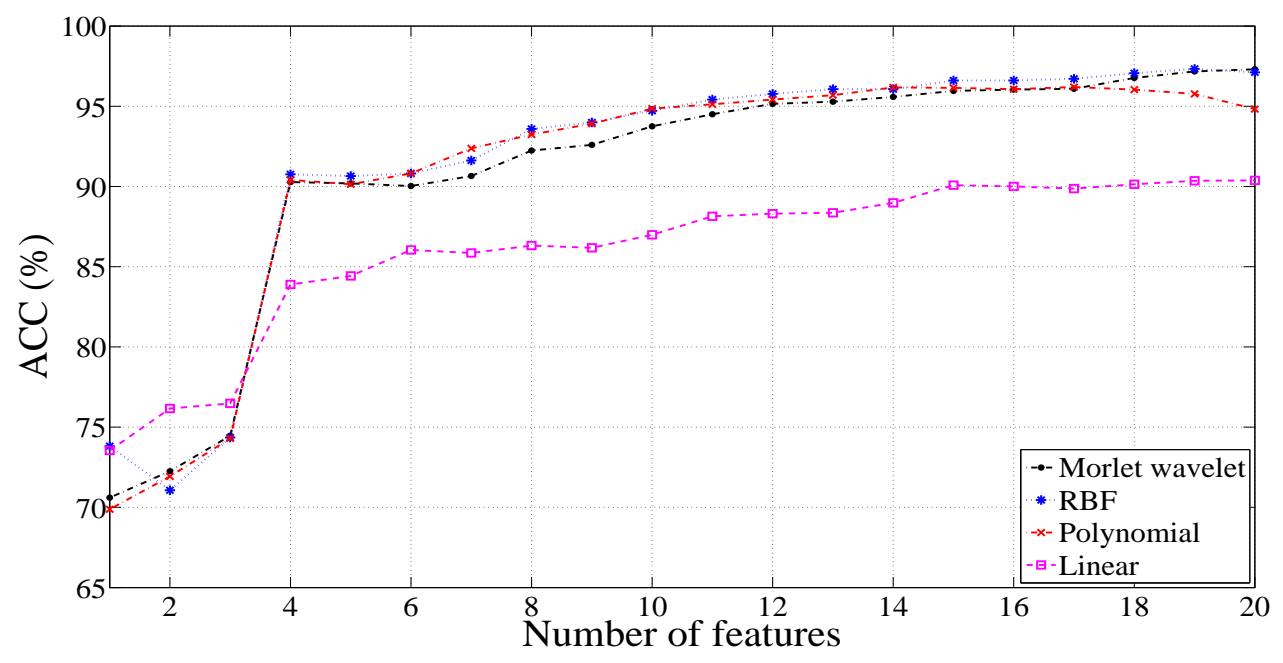

Figure 7. Plot of classification accuracies versus the number of features for Unbalanced Dataset 2 (length of the signal = 500 samples). 


\subsubsection{Results for Balanced Dataset 1}

In this dataset, we use 500 HRV segments from the MIT-BIH NSR dataset of normal subjects and $500 \mathrm{HRV}$ segments from the BIDMC dataset of CHF patients. Classification accuracies corresponding to the used number of features are presented in Figure 8. The highest classification accuracies for linear, Morlet wavelet, RBF and polynomial kernels are $96.60 \%$ using 18 features, $99.4 \%$ using 15 features, 99.5\% using 15 features and $98.4 \%$ using 11 features, respectively. Other computed classification parameters, namely specificity and sensitivity, are provided in Table 6.

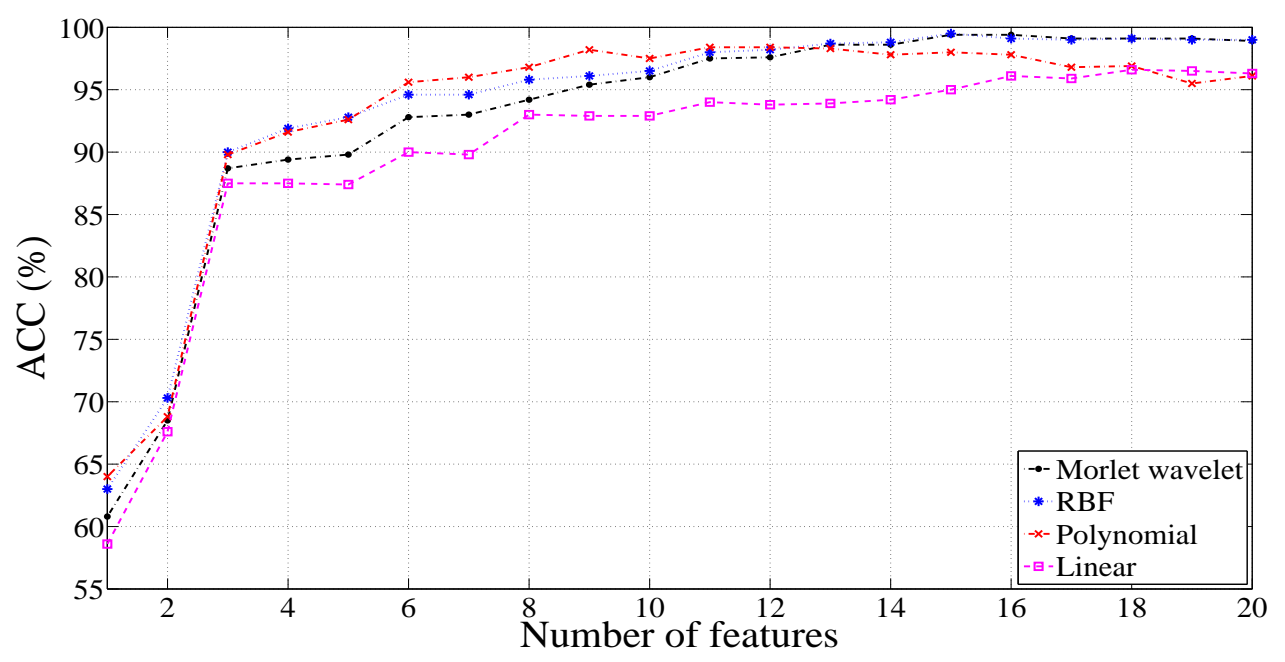

Figure 8. Plot of classification accuracies versus number of features for Balanced Dataset 1 (length of the signal $=500$ samples).

\subsubsection{Results for Balanced Dataset 2}

This dataset has 500 normal HRV segments from the Fantasia dataset and 500 CHF HRV segments from the BIDMC dataset. Classification accuracies obtained for this dataset are shown in Figure 9. The highest values of sensitivity, specificity and accuracy obtained using LS-SVM for different kernels are summarized in Table 6.

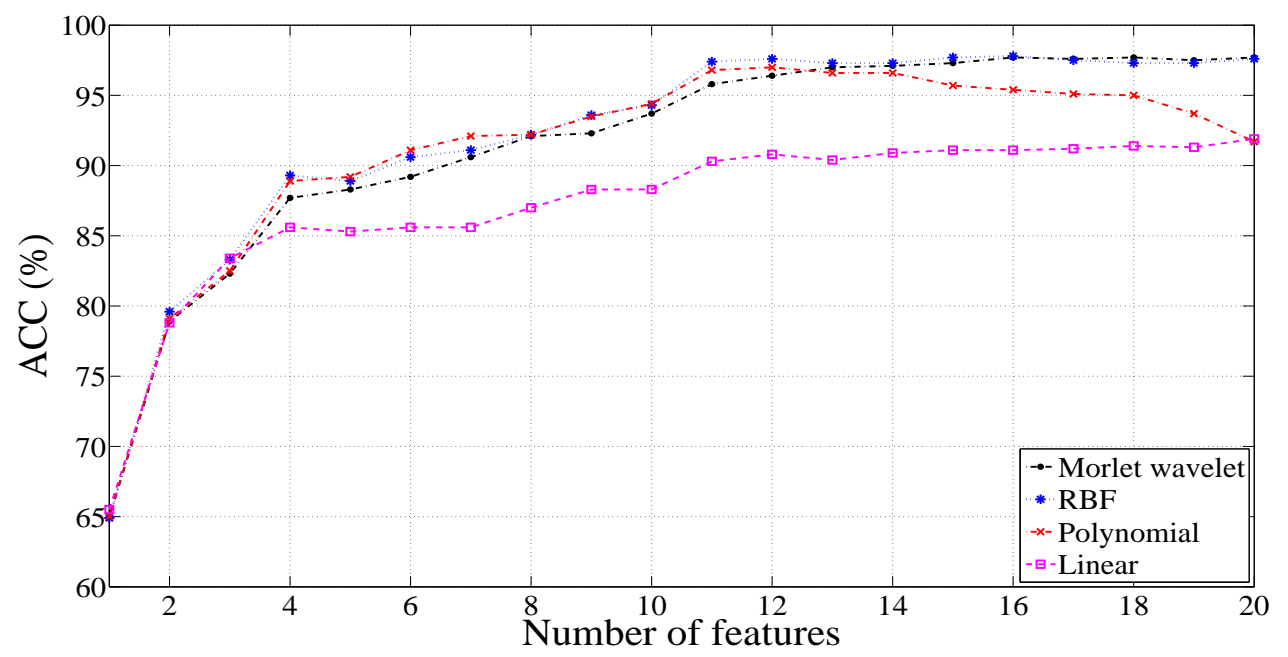

Figure 9. Plot of accuracies versus number of features for Balanced Dataset 2 (signal length = 500 samples).

\subsection{Results with a Signal Length of 1000 Samples}

For a signal length of 1000 samples, again, we have made four different combinations of dataset as described in Section 3.1. We have used the same parameters for AFEnt and APEnt and the same ranking 
method, classifier and kernel functions as in Section 3.1. The highest classification performances for different combinations of datasets for a signal length of 1000 samples can be seen in Table 8 .

Table 8. Classification performance of the LS-SVM classifier for various combinations of dataset (signal length $=1000$ samples) with different kernel functions.

\begin{tabular}{|c|c|c|c|c|c|c|}
\hline $\begin{array}{l}\text { Combinations } \\
\text { of Datasets }\end{array}$ & Kernels & Kernel Parameters & $\begin{array}{l}\text { Number of } \\
\text { Features }\end{array}$ & Sensitivity (\%) & Specificity (\%) & $\operatorname{ACC}(\%)$ \\
\hline \multirow{4}{*}{$\begin{array}{l}\text { Unbalanced } \\
\text { Dataset } 1\end{array}$} & Morlet wavelet & \multirow{4}{*}{$\begin{array}{c}l=7.7, z_{0}=0.25 \\
\text { Order }=3 \\
\sigma=1.8\end{array}$} & 20 & 97.95 & 98.07 & 98.01 \\
\hline & Polynomial & & 17 & 96.70 & 97.54 & 97.13 \\
\hline & RBF & & 19 & 98.01 & 97.95 & 97.98 \\
\hline & Linear & & 20 & 91.22 & 94.44 & 92.88 \\
\hline \multirow{4}{*}{$\begin{array}{l}\text { Unbalanced } \\
\text { Dataset } 2\end{array}$} & Morlet wavelet & \multirow{4}{*}{$\begin{array}{c}l=6.4, z_{0}=0.25 \\
\text { Order }=3 \\
\sigma=1.4\end{array}$} & 20 & 98.75 & 92.80 & 97.95 \\
\hline & Polynomial & & 11 & 96.76 & 95.60 & 96.60 \\
\hline & RBF & & 20 & 98.57 & 94.00 & 97.95 \\
\hline & Linear & & 18 & 92.65 & 84.80 & 91.60 \\
\hline \multirow{4}{*}{$\begin{array}{l}\text { Balanced } \\
\text { Dataset } 1\end{array}$} & Morlet wavelet & \multirow{4}{*}{$\begin{array}{c}l=6, z_{0}=0.25 \\
\text { Order }=3 \\
\sigma=1\end{array}$} & 16 & 100.00 & 99.60 & 99.80 \\
\hline & Polynomial & & 10 & 99.20 & 98.40 & 98.80 \\
\hline & RBF & & 16 & 100.00 & 99.60 & 99.80 \\
\hline & Linear & & 18 & 97.20 & 99.60 & 98.40 \\
\hline \multirow{4}{*}{$\begin{array}{l}\text { Balanced } \\
\text { Dataset } 2\end{array}$} & Morlet wavelet & \multirow{4}{*}{$\begin{array}{c}l=7.9, z_{0}=0.25 \\
\text { Order }=3 \\
\sigma=1.2\end{array}$} & 20 & 98.40 & 98.40 & 98.40 \\
\hline & Polynomial & & 10 & 98.80 & 96.80 & 97.80 \\
\hline & RBF & & 20 & 97.20 & 98.40 & 97.80 \\
\hline & Linear & & 18 & 94.00 & 92.80 & 93.40 \\
\hline
\end{tabular}

\subsection{Results with a 2000-Sample Signal Length}

We also have formed four different combinations of dataset for a signal length of 2000 samples as explained in Section 3.1. In this case, the same parameters are selected for AFEnt and APEnt. For this case, we have also applied the same ranking method, classifier and kernel functions as described in Section 3.1. For a signal length of 2000, the highest obtained values of sensitivity, specificity and accuracy are provided in Table 9.

Table 9. Classification performance of the LS-SVM classifier for various combinations of dataset (signal length $=2000$ samples) with different kernel functions.

\begin{tabular}{|c|c|c|c|c|c|c|}
\hline $\begin{array}{l}\text { Combinations } \\
\text { of Datasets }\end{array}$ & Kernels & Kernel Parameters & $\begin{array}{l}\text { Number of } \\
\text { Features }\end{array}$ & Sensitivity (\%) & Specificity (\%) & $\operatorname{ACC}(\%)$ \\
\hline \multirow{4}{*}{$\begin{array}{l}\text { Unbalanced } \\
\text { Dataset } 1\end{array}$} & Morlet wavelet & \multirow{4}{*}{$\begin{array}{c}l=7.1, z_{0}=0.25 \\
\text { Order }=3 \\
\sigma=1.4\end{array}$} & 15 & 97.51 & 97.78 & 97.65 \\
\hline & Polynomial & & 15 & 95.39 & 96.84 & 96.14 \\
\hline & $\mathrm{RBF}$ & & 16 & 97.76 & 97.67 & 97.71 \\
\hline & Linear & & 20 & 92.41 & 95.32 & 93.91 \\
\hline \multirow{4}{*}{$\begin{array}{l}\text { Unbalanced } \\
\text { Dataset } 2\end{array}$} & Morlet wavelet & \multirow{4}{*}{$\begin{array}{c}l=6, z_{0}=0.25 \\
\text { Order }=3 \\
\sigma=1.3\end{array}$} & 19 & 98.38 & 91.92 & 97.52 \\
\hline & Polynomial & & 11 & 96.77 & 92.82 & 96.23 \\
\hline & RBF & & 19 & 98.38 & 91.92 & 97.52 \\
\hline & Linear & & 19 & 92.54 & 85.64 & 91.59 \\
\hline \multirow{4}{*}{$\begin{array}{l}\text { Balanced } \\
\text { Dataset } 1\end{array}$} & Morlet wavelet & \multirow{4}{*}{$\begin{array}{c}l=7.6, z_{0}=0.25 \\
\text { Order }=3 \\
\sigma=1.8\end{array}$} & 16 & 98.40 & 100.00 & 99.20 \\
\hline & Polynomial & & 9 & 99.17 & 98.33 & 98.80 \\
\hline & RBF & & 16 & 98.40 & 100.00 & 99.20 \\
\hline & Linear & & 19 & 98.46 & 99.17 & 98.78 \\
\hline \multirow{4}{*}{$\begin{array}{l}\text { Balanced } \\
\text { Dataset } 2\end{array}$} & Morlet wavelet & \multirow{4}{*}{$\begin{array}{c}l=8, z_{0}=0.25 \\
\text { Order }=3 \\
\sigma=1.6\end{array}$} & 20 & 98.40 & 99.23 & 98.82 \\
\hline & Polynomial & & 9 & 96.79 & 95.96 & 96.41 \\
\hline & $\mathrm{RBF}$ & & 20 & 98.40 & 99.23 & 98.82 \\
\hline & Linear & & 20 & 96.73 & 95.06 & 95.95 \\
\hline
\end{tabular}

\section{Discussion}

In the present work, we have analyzed the complexity of CHF and normal HRV signals at different frequency scales obtained using FAWT. The FAWT is applied to the CHF and normal HRV signals 
to decompose them into sub-band signals. We have used FAWT-based decomposition due to its flexibility to control the $Q$-factor $(Q)$, redundancy and dilation factor $[29,30]$. We have combined these sub-band signals so that we can observe the complexity of HRV signals at different frequency scales. For complexity measurement, AFEnt and APEnt are computed from different frequency scaled signals. We observed that AFEnt is more suitable to analyze the complexity of CHF and normal HRV signals, as it showed higher accuracy as compared to APEnt, and it can be seen in Table 3. Most of the frequency scaled signals (except $\mathrm{SH}_{1}$ and $\mathrm{SH}_{2}$ in Table 4) showed lower mean values of AFEnt for CHF HRV signals. These results shows lower complexity of CHF HRV signals as compared to the normal HRV signals for most of the frequency scales. The reduced complexity of CHF HRV signals may be the reflection of the reduced parasympathetic modulation of heart rate [58].

The comparison of our methodology with the other existing works is summarized in Table 10. In [5], the normal and CHF HRV signals are analyzed using the Poincare plot and time domain features. The positive predictive accuracy of $98.19 \%$ is achieved for time domain features with the Back Propagation Neural Network (BPNN) classifier. Time domain- and frequency domain-based features are computed to separate normal and CHF classes in [59]. The Classification And Regression Tree (CART) method provided $96.4 \%$ classification accuracy. The Detrended Fluctuation Analysis (DFA)-based features with SVM yielded $96 \%$ classification accuracy to discriminate normal and CHF HRV signals in [4]. In [60], the authors have studied time domain features, frequency domain features and bispectrum features to analyze HRV signals of CHF and normal subjects. They incorporated Genetic Algorithm (GA) and SVM classifier in their method and obtained 98.79\% classification accuracy. In [61], the standard HRV measures, nonlinear parameters and wavelet-based measures are used to distinguish CHF and normal HRV signals. They achieved $91.56 \%$ accuracy using 27 selected features with the SVM classifier. Two balanced and two unbalanced datasets of HRV signals (CHF and normal subjects) are studied in [58]. First, the signals are decomposed using the EMD method; then, 13 non-linear parameters are computed from these decomposed intrinsic mode functions. They achieved 97.64\% accuracy for Unbalanced Dataset 1 with 22 features, 95.79\% accuracy for Unbalanced Dataset 2 with 35 features, 96.7\% accuracy for Balanced Dataset 1 with 12 features and $94 \%$ accuracy for Balanced Dataset 2 with 11 features.

In this work, we have analyzed the HRV signals of CHF and normal subjects with 500, 1000 and 2000 sample lengths, while the authors in [58] have used a 2000 sample length in their study. We have achieved better classification accuracy with less features as compared to [58]. The computational complexity of our method is lesser than [58], as we have computed only two parameters (AFEnt and APEnt), while [58] have computed 13 non-linear parameters. Moreover, we have also achieved good classification accuracies for a 1000-sample signal length and a 500-sample signal length. Therefore, our methodology is suitable for short-term HRV signals, which can provide great help to the doctors and clinicians during their diagnosis of CHF patients. The proposed methodology requires HRV signals of a small length as compared to [58], which is desired in biomedical signal recording.

The limitation of our work is that we have used only $15 \mathrm{CHF}$ subjects in this study. Our developed algorithm needs to be tested with a huge dataset before clinical usage. Furthermore, the kernel parameters need to be selected automatically to achieve the highest performance instead of trial and error selection. 
Table 10. Summary of automated diagnosis of CHF based on HRV signals. NSR, Normal Sinus Rhythm; DFA, Detrended Fluctuation Analysis; EMD, Empirical Mode Decomposition; UD, Unbalanced Dataset; BD, Balanced Dataset.

\begin{tabular}{|c|c|c|c|c|c|c|c|}
\hline $\begin{array}{l}\text { Authors, Year, } \\
\text { and Reference }\end{array}$ & $\begin{array}{l}\text { Studied Dataset } \\
\text { Normal Subject }\end{array}$ & CHF Patient & Applied Methods & $\begin{array}{l}\text { Number of } \\
\text { Subjects/HRV Signals }\end{array}$ & Classifier Used & $\begin{array}{l}\text { Total No. of } \\
\text { Features }\end{array}$ & Results \\
\hline $\begin{array}{l}\text { Khaled et al. } \\
\text { (2006) [5] }\end{array}$ & $\begin{array}{l}\text { MIT-BIH NSR and } \\
\text { NSR RR interval } \\
\text { databases }\end{array}$ & $\begin{array}{l}\text { BIDMC CHF and } \\
\text { CHF RR interval } \\
\text { databases }\end{array}$ & $\begin{array}{l}\text { Time domain parameters and } \\
\text { Poincare plots }\end{array}$ & $\begin{array}{l}\text { Total } 600 \text { short-term } \\
\text { HRV signals }\end{array}$ & BPNN & 11 & $\begin{array}{l}\text { Positive predictive } \\
\text { accuracy }=98.19 \%\end{array}$ \\
\hline $\begin{array}{l}\text { Pecchia et al. } \\
\text { (2011) [59] }\end{array}$ & $\begin{array}{l}\text { NSR RR interval } \\
\text { database }\end{array}$ & $\begin{array}{l}\text { CHF RR interval } \\
\text { database }\end{array}$ & $\begin{array}{l}\text { Time and frequency domain } \\
\text { based parameters }\end{array}$ & $\begin{array}{l}54 \text { normal subjects and } \\
29 \text { CHF patients }\end{array}$ & CART & 9 & $\mathrm{ACC}=96.4 \%$ \\
\hline $\begin{array}{l}\text { Jong et al. } \\
(2011)[4]\end{array}$ & $\begin{array}{l}\text { NSR RR interval } \\
\text { database }\end{array}$ & $\begin{array}{l}\text { CHF RR interval } \\
\text { database }\end{array}$ & DFA-based parameters & $\begin{array}{l}54 \text { normal subjects and } \\
29 \text { CHF patients }\end{array}$ & SVM & $\begin{array}{l}\text { DFA-based } \\
\text { features }\end{array}$ & $\mathrm{ACC}=96 \%$ \\
\hline $\begin{array}{l}\text { Yu et al. } \\
\text { (2012) [60] }\end{array}$ & $\begin{array}{l}\text { NSR RR interval } \\
\text { database }\end{array}$ & $\begin{array}{l}\text { CHF RR interval } \\
\text { database }\end{array}$ & $\begin{array}{l}\text { Time, frequency domain parameters } \\
\text { and bispectrum parameters }\end{array}$ & $\begin{array}{l}54 \text { normal subjects and } \\
29 \text { CHF patients }\end{array}$ & SVM & 16 & $\mathrm{ACC}=98.79 \%$ \\
\hline $\begin{array}{l}\text { Narin et al. } \\
(2014)[61]\end{array}$ & $\begin{array}{l}\text { NSR RR interval } \\
\text { database }\end{array}$ & $\begin{array}{l}\text { CHF RR interval } \\
\text { database }\end{array}$ & $\begin{array}{l}\text { Standard HRV measures, nonlinear } \\
\text { parameters and wavelet-based measures }\end{array}$ & $\begin{array}{l}54 \text { normal subjects and } \\
29 \text { CHF patients }\end{array}$ & SVM & 27 & $\mathrm{ACC}=91.56 \%$ \\
\hline $\begin{array}{l}\text { Acharya et al. } \\
\text { (2016) [58] }\end{array}$ & $\begin{array}{l}\text { MIT-BIH NSR and } \\
\text { Fantasia databases }\end{array}$ & $\begin{array}{l}\text { BIDMC CHF } \\
\text { database }\end{array}$ & $\begin{array}{l}\text { EMD, } 13 \text { nonlinear parameters } \\
\text { HRV signal length }=2000 \text { samples }\end{array}$ & $\begin{array}{l}58 \text { normal subjects and } \\
15 \text { CHF patients }\end{array}$ & SVM & $\begin{array}{l}22 \\
35 \\
12 \\
11\end{array}$ & $\begin{array}{l}\text { UD 1, ACC }=97.64 \% \\
\text { UD 2, ACC }=95.79 \% \\
\text { BD 1, ACC }=96.7 \% \\
\text { BD 2, ACC }=94 \%\end{array}$ \\
\hline $\begin{array}{l}\text { In the present } \\
\text { work }\end{array}$ & $\begin{array}{l}\text { MIT-BIH NSR and } \\
\text { Fantasia databases }\end{array}$ & $\begin{array}{l}\text { BIDMC CHF } \\
\text { database }\end{array}$ & $\begin{array}{l}\text { FAWT, AFEnt and APEnt } \\
\text { HRV signal length }=500 \text { samples }\end{array}$ & $\begin{array}{l}58 \text { normal subjects and } \\
15 \text { CHF patients }\end{array}$ & LS-SVM & $\begin{array}{l}18 \\
19 \\
11 \\
12\end{array}$ & $\begin{array}{l}\text { UD 1, ACC }=98.21 \% \\
\text { UD 2, ACC }=97.33 \% \\
\text { BD 1, ACC }=98.40 \% \\
\text { BD 2, ACC }=97 \%\end{array}$ \\
\hline
\end{tabular}




\section{Conclusions}

In this work, the CHF and normal subjects are analyzed using 500, 1000 and 2000 samples of HRV signals. The AFEnt and APEnt are computed at different frequency scales of HRV signals (CHF and normal class). To get the different frequency scales of HRV signals, we have used the sub-band signals obtained by the decomposition of HRV signals using the FAWT method. The HRV signals are decomposed up to the fifth level. Our methodology performed well for all three signal lengths of HRV signals. We have tested our methodology with two combinations of unbalanced and balanced datasets. The presented method performed significantly well for all four combinations of datasets. Moreover, we have used the LS-SVM classifier with 10-fold cross-validation method and tested it with four different kernels (linear, RBF, polynomial and Morlet wavelet), which increases the robustness of our method. This method may assist clinicians in the faster diagnosis of CHF patients and to provide timely treatment. Thus, it may be a useful tool in improving the quality of life of CHF-affected patients.

Author Contributions: Ram Bilas Pachori and U. Rajendra Acharya designed the research problem and the methodology. Mohit Kumar performed the research work. Mohit Kumar wrote the manuscript and all authors edited the manuscript. All authors have read and approved the final manuscript.

Conflicts of Interest: The authors declare no conflict of interest.

\section{References}

1. Ponikowski, P.; Anker, S.D.; AlHabib, K.F.; Cowie, M.R.; Force, T.L.; Hu, S.; Jaarsma, T.; Krum, H.; Rastogi, V.; Rohde, L.E.; et al. Heart failure: preventing disease and death worldwide. ESC Heart Fail. 2014, 1, 4-25.

2. National Heart, Lung and Blood Institute, What Is Heart Failure? 2015. Available online: https://www. nhlbi.nih.gov/health/health-topics/topics/hf/ (accessed on 15 January 2017).

3. Pazos-López, P.; Peteiro-Vázquez, J.; Carcía-Campos, A.; García-Bueno, L.; de Torres, J.P.A.; Castro-Beiras, A. The causes, consequences, and treatment of left or right heart failure. Vasc. Health Risk Manag. 2011, 7, 237-254.

4. Jong, T.L.; Chang, B.; Kuo, C.D. Optimal timing in screening patients with congestive heart failure and healthy subjects during circadian observation. Ann. Biomed. Eng. 2011, 39, 835-849.

5. Khaled, A.S.; Owis, M.I.; Mohamed, A.S.A. Employing time-domain methods and Poincaré plot of heart rate variability signals to detect congestive heart failure. BIME J. 2006, 6, 35-41.

6. Acharya, U.R.; Kannathal, N.; Krishnan, S.M. Comprehensive analysis of cardiac health using heart rate signals. Physiol. Meas. 2004, 25, 1139-1151.

7. Sood, S.; Kumar, M.; Pachori, R.B.; Acharya, U.R. Application of empirical mode decomposition-based features for analysis of normal and CAD heart rate signals. J. Mech. Med. Biol. 2016, 16, 1640002.

8. Giri, D.; Acharya, U.R.; Martis, R.J.; Sree, S.V.; Lim, T.C.; Vi, T.A.; Suri, J.S. Automated diagnosis of coronary artery disease affected patients using LDA, PCA, ICA and discrete wavelet transform. Knowl. Based Syst. 2013, 37, 274-282.

9. Patidar, S.; Pachori, R.B.; Acharya, U.R. Automated diagnosis of coronary artery disease using tunable-Q wavelet transform applied on heart rate signals. Knowl. Based Syst. 2015, 82, 1-10.

10. Chua, K.C.; Chandran, V.; Acharya, U.R.; Lim, C.M. Cardiac state diagnosis using higher order spectra of heart rate variability. J. Med. Eng. Technol. 2008, 32, 145-155.

11. Acharya, U.R.; Sankaranarayanan, M.; Nayak, J.; Xiang, C.; Tamura, T. Automatic identification of cardiac health using modeling techniques: A comparative study. Inf. Sci. 2008, 178, 4571-4582.

12. Stein, P.K.; Domitrovich, P.P.; Kleiger, R.E.; Schechtman, K.B.; Rottman, J.N. Clinical and demographic determinants of heart rate variability in patients post myocardial infarction: insights from the cardiac arrhythmia suppression trial (CAST). Clin. Cardiol. 2000, 23, 187-194.

13. Mussalo, H.; Vanninen, E.; Ikäheimo, R.; Laitinen, T.; Laakso, M.; Länsimies, E.; Hartikainen, J. Heart rate variability and its determinants in patients with severe or mild essential hypertension. Clin. Physiol. 2001, 21, 594-604.

14. Malliani, A.; Lombardi, F.; Pagani, M.; Cerutti, S. Power spectral analysis of cardiovascular variability in patients at risk for sudden cardiac death. J. Cardiovasc. Electrophysiol. 1994, 5, 274-286. 
15. Pachori, R.B.; Avinash, P.; Shashank, K.; Sharma, R.; Acharya, U.R. Application of empirical mode decomposition for analysis of normal and diabetic RR-interval signals. Expert Syst. Appl. 2015, 42, 4567-4581.

16. Acharya, U.R.; Vidya, K.S.; Ghista, D.N.; Lim, W.J.E.; Molinari, F.; Sankaranarayanan, M. Computer-aided diagnosis of diabetic subjects by heart rate variability signals using discrete wavelet transform method. Knowl. Based Syst. 2015, 81, 56-64.

17. Pachori, R.B.; Kumar, M.; Avinash, P.; Shashank, K.; Acharya, U.R. An improved online paradigm for screening of diabetic patients using RR-interval signals. J. Mech. Med. Biol. 2016, 16, 1640003.

18. Nolan, J.; Batin, P.D.; Andrews, R.; Lindsay, S.J.; Brooksby, P.; Mullen, M.; Baig, W.; Flapan, A.D.; Cowley, A.; Prescott, R.J.; et al. Prospective study of heart rate variability and mortality in chronic heart failure. Circulation 1998, 98, 1510-1516.

19. Hadase, M.; Azuma, A.; Zen, K.; Asada, S.; Kawasaki, T.; Kamitani, T.; Kawasaki, S.; Sugihara, H.; Matsubara, H. Very low frequency power of heart rate variability is a powerful predictor of clinical prognosis in patients with congestive heart failure. Circ. J. 2004, 68, 343-347.

20. Musialik-Łydka, A.; Sredniawa, B.; Pasyk, S. Heart rate variability in heart failure. Kardiol. Polska 2003, 58, 10-16.

21. Asyali, M.H. Discrimination Power of Long-Term Heart Rate Variability Measures. In Proceedings of the 25th Annual International Conference of the IEEE Engineering in Medicine and Biology Society, Cancun, Mexico, 17-21 September 2003; Volume 1, pp. 200-203.

22. Guzzetti, S.; Mezzetti, S.; Magatelli, R.; Porta, A.; Angelis, G.D.; Rovelli, G.; Malliani, A. Linear and non-linear $24 \mathrm{~h}$ heart rate variability in chronic heart failure. Auton. Neurosci. Basic Clin. 2000, 86, 114-119.

23. Melillo, P.; Luca, N.D.; Bracale, M.; Pecchia, L. Classification tree for risk assessment in patients suffering from congestive heart failure via long-term heart rate variability. IEEE J. Biomed. Health Inform. 2013, 17, 727-733.

24. Arbolishvili, G.N.; Mareev, V.I.; Orlova, I.; Belenkov, I.N. Heart rate variability in chronic heart failure and its role in prognosis of the disease. Kardiologiia 2006, 46, 4-11.

25. Maestri, R.; Pinna, G.D.; Accardo, A.; Allegrini, P.; Balocchi, R.; D’addio, G.; Ferrario, M.; Menicucci, D.; Porta, A.; Sassi, R.; et al. Nonlinear Indices of Heart Rate Variability in Chronic Heart Failure Patients: Redundancy and Comparative Clinical Value. J. Cardiovasc. Electrophysiol. 2007, 18, 425-433.

26. Thakre, T.P.; Smith, M.L. Loss of lag-response curvilinearity of indices of heart rate variability in congestive heart failure. BMC Cardiovasc. Disord. 2006, 6, 27.

27. Shahbazi, F.; Asl, B.M. Generalized discriminant analysis for congestive heart failure risk assessment based on long-term heart rate variability. Comput. Methods Programs Biomed. 2015, 122, 191-198.

28. Liu, G.; Wang, L.; Wang, Q.; Zhou, G.; Wang, Y.; Jiang, Q. A new approach to detect congestive heart failure using short-term heart rate variability measures. PLOS ONE 2014, 9, e93399.

29. Bayram, I. An analytic wavelet transform with a flexible time-frequency covering. IEEE Trans. Signal Process. 2013, 61, 1131-1142.

30. Zhang, C.; Li, B.; Chen, B.; Cao, H.; Zi, Y.; He, Z. Weak fault signature extraction of rotating machinery using flexible analytic wavelet transform. Mech. Syst. Signal Process. 2015, 64-65, 162-187.

31. Theodoridis, S.; Koutroumbas, K. Feature Selection. In Pattern Recognition, 2nd ed.; Academic Press: San Diego, CA, USA, 2003; pp. 163-205.

32. Suykens, J.A.K.; Vandewalle, J. Least squares support vector machine classifiers. Neural Process. Lett. 1999, 9, 293-300.

33. Baim, D.S.; Colucci, W.S.; Monrad, E.S.; Smith, H.S.; Wright, R.F.; Lanoue, A.; Gauthier, D.F.; Ransil, B.J.; Grossman, W.; Braunwald, E. Survival of patients with severe congestive heart failure treated with oral milrinone. J. Am. Coll. Cardiol. 1986, 7, 661-670.

34. Goldberger, A.L.; Amaral, L.A.N.; Glass, L.; Hausdorff, J.M.; Ivanov, P.C.; Mark, R.G.; Mietus, J.E.; Moody, G.B.; Peng, C.K.; Stanley, H.E. Physiobank, physiotoolkit, and physionet: Components of a new research resource for complex physiologic signals. Circulation 2000, 101, e215-e220.

35. Iyengar, N.; Peng, C.K.; Morin, R.; Goldberger, A.L.; Lipsitz, L.A. Age-related alterations in the fractal scaling of cardiac interbeat interval dynamics. Am. J. Physiol. 1996, 271, R1078-R1084.

36. Bandt, C.; Pompe, B. Permutation entropy: A natural complexity measure for time series. Phys. Rev. Lett. 2002, 88, 174102. 
37. Zanin, M.; Zunino, L.; Rosso, O.A.; Papo, D. Permutation entropy and its main biomedical and econophysics applications: A review. Entropy 2012, 14, 1553-1577.

38. Li, X.; Ouyang, G.; Richards, D.A. Predictability analysis of absence seizures with permutation entropy. Epilepsy Res. 2007, 77, 70-74.

39. Chen, W.; Wang, Z.; Xie, H.; Yu, W. Characterization of surface EMG signal based on fuzzy entropy. IEEE Trans. Neural Syst. Rehabil. Eng. 2007, 15, 266-272.

40. Kumar, M.; Pachori, R.B.; Acharya, U.R. An efficient automated technique for CAD diagnosis using flexible analytic wavelet transform and entropy features extracted from HRV signals. Expert Syst. Appl. 2016, 63, 165-172.

41. Bayram, I.; Selesnick, I.W. Frequency-domain design of overcomplete rational dilation wavelet transform. IEEE Trans. Signal Process. 2009, 57, 2957-2972.

42. Kumar, M.; Pachori, R.B.; Acharya, U.R. Characterization of coronary artery disease using flexible analytic wavelet transform applied on ECG signals. Biomed. Signal Process. Control 2017, 31, 301-308.

43. Pachori, R.B.; Hewson, D.; Snoussi, H.; Duchene, J. Postural Time-Series Analysis Using Empirical Mode Decomposition and Second-Order Difference Plots. In Proceedings of the IEEE International Conference on Acoustics, Speech and Signal Processing, Taipei, Taiwan, 19-24 April 2009; pp. 537-540.

44. Duda, R.O.; Hart, P.E.; Stork, D.G. Pattern Classification, 2nd ed.; John Willey \& Sons: Hoboken, NJ, USA, 2000.

45. Gestel, T.V.; Suykens, J.A.K.; Lanckriet, G.; Lambrechts, A.; Moor, B.D.; Vandewalle, J. Bayesian framework for least-squares support vector machine classifiers, Gaussian processes, and kernel Fisher discriminant analysis. Neural Comput. 2002, 14, 1115-1147.

46. Khandoker, A.H.; Lai, D.T.H.; Begg, R.K.; Palaniswami, M. Wavelet-based feature extraction for support vector machines for screening balance impairments in the elderly. IEEE Trans. Neural Syst. Rehabil. Eng. 2007, 15, 587-597.

47. Bajaj, V.; Pachori, R.B. Classification of seizure and nonseizure EEG signals using empirical mode decomposition. IEEE Trans. Inf. Technol. Biomed. 2012, 16, 1135-1142.

48. Zavar, M.; Rahati, S.; Akbarzadeh-T, M.R.; Ghasemifard, H. Evolutionary model selection in a wavelet-based support vector machine for automated seizure detection. Expert Syst. Appl. 2011, 38, 10751-10758.

49. Azar, A.T.; El-Said, S.A. Performance analysis of support vector machines classifiers in breast cancer mammography recognition. Neural Comput. Appl. 2014, 24, 1163-1177.

50. McKnight, P.E.; Najab, J. Kruskal-Wallis Test. Corsini Encycl. Psychol. 2010, doi:10.1002/9780470479216.

51. Bhati, D.; Sharma, M.; Pachori, R.B.; Gadre, V.M. Time-frequency localized three-band biorthogonal wavelet filter bank using semidefinite relaxation and nonlinear least squares with epileptic seizure EEG signal classification. Digit. Signal Process. 2017, 62, 259-273.

52. Sharma, R.; Pachori, R.B. Classification of epileptic seizures in EEG signals based on phase space representation of intrinsic mode functions. Expert Syst. Appl. 2015, 42, 1106-1117.

53. Pachori, R.B. Discrimination between ictal and seizure-free EEG signals using empirical mode decomposition. Res. Lett. Signal Process. 2008, 2008, 293056.

54. Kohavi, R. A Study of Cross-Validation and Bootstrap for Accuracy Estimation and Model Selection. In Proceedings of the 14th International Joint Conference on Artificial Intelligence, Montreal, QC, Canada, 20-25 August 1995; pp. 1137-1143.

55. Bhattacharyya, A.; Pachori, R.B. A multivariate approach for patient-specific EEG seizure detection using empirical wavelet transform. IEEE Trans. Biomed. Eng. 2017, doi:10.1109/TBME.2017.2650259.

56. Sharma, R.; Pachori, R.B.; Acharya, U.R. Application of entropy measures on intrinsic mode functions for the automated identification of focal electroencephalogram signals. Entropy 2015, 17, 669-691.

57. Sharma, R.; Pachori, R.B.; Acharya, U.R. An integrated index for the identification of focal electroencephalogram signals using discrete wavelet transform and entropy measures. Entropy 2015, 17, 5218-5240.

58. Acharya, U.R.; Fujita, H.; Sudarshan, V.K.; Oh, S.L.; Muhammad, A.; Koh, J.E.W.; Tan, J.H.; Chua, C.K.; Chua, K.P.; Tan, R.S. Application of empirical mode decomposition (EMD) for automated identification of congestive heart failure using heart rate signals. Neural Comput. Appl. 2016, 1-22, doi:10.1007/s00521-016-2612-1.

59. Pecchia, L.; Melillo, P.; Sansone, M.; Bracale, M. Discrimination power of short-term heart rate variability measures for CHF assessment. IEEE Trans. Inf. Technol. Biomed. 2011, 15, 40-46. 
60. Yu, S.N.; Lee, M.Y. Bispectral analysis and genetic algorithm for congestive heart failure recognition based on heart rate variability. Comput. Biol. Med. 2012, 42, 816-825.

61. Narin, A.; Isler, Y.; Ozer, M. Investigating the performance improvement of HRV indices in CHF using feature selection methods based on backward elimination and statistical significance. Comput. Biol. Med. 2014, $45,72-79$.

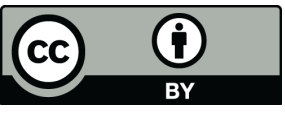

(C) 2017 by the authors; licensee MDPI, Basel, Switzerland. This article is an open access article distributed under the terms and conditions of the Creative Commons Attribution (CC BY) license (http:/ / creativecommons.org/licenses/by/4.0/). 